\title{
Overall precision test of near infrared spectroscopy on mango fruits (Mangifera indica CV. 'Nam Dok Mai Si Thong') by on-line and off-line systems
}

\author{
Wachiraya Lekhawattana ${ }^{1 *}$, and Panmanas Sirisomboon ${ }^{2}$ \\ ${ }^{1}$ King Mongkut's Institute of Technology Ladkrabang, Department of Agricultural Engineering, \\ Faculty of Engineering, Bangkok, Thailand. \\ ${ }^{2}$ King Mongkut's Institute of Technology Ladkrabang, NIR Spectroscopy Research Center for \\ Agricultural Products and Foods, Department of Agricultural Engineering, \\ Faculty of Engineering, Bangkok, Thailand.
}

\begin{abstract}
The near infrared (NIR) spectroscopy both on-line and off-line scanning was applied on mango fruits (Mangifera indica CV. 'Nam dok mai- si Thong') for the overall precision test. The reference parameter was total soluble solids content (Brix value). The results showed that the off-line scanning had a higher accuracy than on-line scanning. The scanning repeatability of the off-line and on-line systems were 0.00199 and 0.00993 , respectively. The scanning reproducibility of the off-line and online systems were 0.00279 and 0.00513 , respectively. The reference of measurement repeatability was 0.2 . The maximum coefficient of determination $\left(\mathrm{R}^{2}{ }_{\max }\right)$ of the reference measurement was 0.894 .
\end{abstract}

\section{Introduction}

Mango is an important economic crop, which can generate income for farmers in Thailand because of consumption demand in both domestic and international markets. According to the statistics of mangoes exports in 2017, The total production throughout was 2.017 million tons [2]. The most exported mango species include nam dok mai, Khiao Sawiei, Hnuk Klangwan, Chok Anan, Rad and Aok Rong, respectively.

The nam dok mai mango specie is one of the main economic crops in 10 districts of Chiang Mai, such as Phrao, Fang, Chaiprakarn, Chiang Dao, Wiang Haeng, Mae Taeng, Mae Wang, Doi Lo, Doi Tao and Mae Ai. Farmers need to improve the quality of products and maintain the export quality. This action aims to increase the competition capacity and new options for the market, since Peru is currently provide cheaper products, which is considered a competing country for Thailand in Korean, Japanese, Chinese and Malaysian markets [1]. The general criteria that farmers use in exporting nam dok mai mango is to consider the external quality by using the eyesight, such as color, size, skin and external spoilage, etc.

\footnotetext{
* Corresponding author: lekhawattanawachiraya@gmail.com
} 
However, the internal quality such as ripening of mango and sweetness (Brix value) are also one of the important factors with highest priority for consumers when considering the purchase. If consumers want to know the ripening level of mangoes or other fruits, it is necessary to use a measuring tool to measure the ripening value of mangoes. This measuring technique for this type of fruit require cutting or shearing the fruit, which is considered as a Destructive Method. For a sample in the food processing industry with a large sample volume, it is needed to use manpower to measure that takes a long time [4].

Therefore, the considering for the a new nondestructive method for sample testing, is another interesting option for entrepreneurs in the agricultural sector to check the ripening of mango and to ensure the fruit quality from the export date until consumers edible date. Nowadays, nondestructive testing is a widespread method as it can be used to analyze samples quickly. The Near Infrared Spectroscopy (NIR) technique can easily analyze samples with energy saving, time reduction, high safety, reducing pollution from the test. As a result, it reduces production costs in the long run without the need for an expert [3].

However, exporting mango to sell in foreign markets requires long distance transportation leading to quality problems and short shelf-life by reported that when after harvesting mango, which is a climacteric fruit, the mango will change rapidly, affecting the appearance quality and consumers' purchasing decisions, such as color, shape, defects, sweetness, and firmness. Therefore, the objective of this research was to investigate the overall precision test of near infrared (NIR) spectroscopy both on-line and off-line scanning applied on mango fruits (Mangifera Indica $\mathrm{CV}$.'Nam dok mai si thong). The reference parameter was total soluble solids content (Brix value).

\section{Materials and methods}

\subsection{Preparation of raw materials}

"Nam dok mai" mangos at the mature stage (100\% Mature - green) were harvested from a commercial orchard in Chiang Mai. The fruits were selected for uniform, size, color, disease free, and mechanical damage. Each mango weighed about 300-400 g, $16 \mathrm{~cm}$ average length, $6 \mathrm{~cm}$ average width and $7 \mathrm{~cm}$ average thickness. It was harvested during commercial harvesting period. After harvest, it was kept at room temperature. The off-line and on-line scanning was performed on one sample for overall precision test. Mangos were kept at the NIR Spectroscopy Research Center for Agricultural Product and Food, Department of Agricultural Engineering, King Mongkut's Institute of Technology Ladkrabang, at ambient temperature.

\subsection{Measurements of quality}

Off-line scanning with FT-NIR spectrometer was conducted using FT-NIR spectrometer (Multi purpose analyzer (MPA), Bruker, Germany in the form of diffuse reflectance 1 point per 1 sample in the range of $12500-4000 \mathrm{~cm}^{-1}$ or $800-2500 \mathrm{~nm}$. of wave range by 1 scan for 1 spectrum.

On-line scanning with UV-NIR spectrometer was conducted using UV-VIS-NIR spectrometer (Ava Spec ULS2048 - USB2-VA-50, AVANTES, Netherlands) with by 350 $1100 \mathrm{~nm}$.

The mango was delivered via conveyor for scanning using an integrating sphere light source. The spectrum was generated by a spectrometer at a scan time of $9.5 \mathrm{~ms}$. The conveyor speed is $0.1 \mathrm{~m} / \mathrm{s}$. The reflection measurement mode was applied with Teflon as reference 
material. The spectrum with the focal length was about 1-2 cm. distance from the measuring head to the mango fruit.

After scanning the total soluble solids content (TSS) of the mango sample was measured by using a Digital Hand-held "Pocket" refractometer (PAL-1S/No L218454, ATAGO, JAPAN), the value could range from $0-45$ percent brix. The mango pulp was divided into three parts, namely head, middle and tail parts, and the juice of each part was dropped on the refractometer. There were 3 repeated time for each part.

\subsection{Repeatability, reproducibility and maximum coefficient of determination}

The repeatability of NIR scanning was determined by scanning on a sample at the same position for 10 times, then calculating the standard deviation (SD) value of the absorbance for the scanning. The 3 wavenumber from whole spectrum including $10245 \mathrm{~cm}^{-1}(970 \mathrm{~nm}$.), $6897 \mathrm{~cm}^{-1}\left(1440 \mathrm{~nm}\right.$.) and $5569 \mathrm{~cm}^{-1}$ (1900 nm.) which were the vibration bands of $\mathrm{CH}$, water and $\mathrm{OH}$ respectively were selected and the average SD of absorbance in all wavenumber were the repeatability of scanning of the instrument.

The reproducibility of NIR scanning was found from the scanning of the same sample for 10 repeated times, with the reload for every time, then find the standard deviation (SD) of the absorbance from the 10 spectrum at the selected 3 wavelengths and then average.

The repeatability of the measured reference value corresponds to the standard deviation of the differences between the duplicates of reference test. Then the repeatability of measured reference value (Rep) was used to determine the maximum coefficient of determination $\left(\mathrm{R}_{\text {max }}^{2}\right)$, which was calculated using following formula.

$$
R_{\text {max }}^{2}=\frac{S D_{y}^{2}-R e p^{2}}{S D_{y}^{2}}
$$

when $\mathrm{SD}_{\mathrm{y}}^{2}$ is the standard deviation of data of measured value in calibration set, $\mathrm{R}^{2}$ max is possible only when there are no errors in the spectra or the model.

\section{Results and discussion}

\subsection{On-line and off-line near infrared spectroscopy}

The samples had an average spectrum scanned by FT-NIR spectrometer shown in Figure 1. with the interesting wavelength, including the wavelength at $6897 \mathrm{~cm}^{-1}$ and $5569 \mathrm{~cm}^{-1}$, where the wavelength at the wavelength at $6897 \mathrm{~cm}^{-1}$ was a vibration of the bond $\mathrm{O}-\mathrm{H}$ str., and the wavelength at $5569 \mathrm{~cm}^{-1}$ was a vibration of the bond $\mathrm{O}-\mathrm{H}$ str. 
Figure 2. shows the average spectra of mango samples scanned by UV-VIS-NIR spectrometer and the peak of water is at $693 \mathrm{~nm}$. and $953 \mathrm{~nm}$. for mango samples. Table 1 . shows repeatability and reproducibility by FT-NIR spectrometer. From Table 1, there was a preliminary experiment showing with 0.00199 and 0.00279 of repeatability and reproducibility values of the off-line spectrometers and 0.00993 and 0.00513 of repeatability and reproducibility values of the on-line spectrometers, respectively. The repeatability and reproducibility of off-line scanning were less than on-line scanning, which showed that off-line scanning was more accurate than on-line scanning. However, the on-line system could be used in the production line of the mango export system with the maximum coefficient of determination as 0.894 . While, the repeatability of the reference method was equal to 0.2 , and the reference method error was only 10.6 percent.

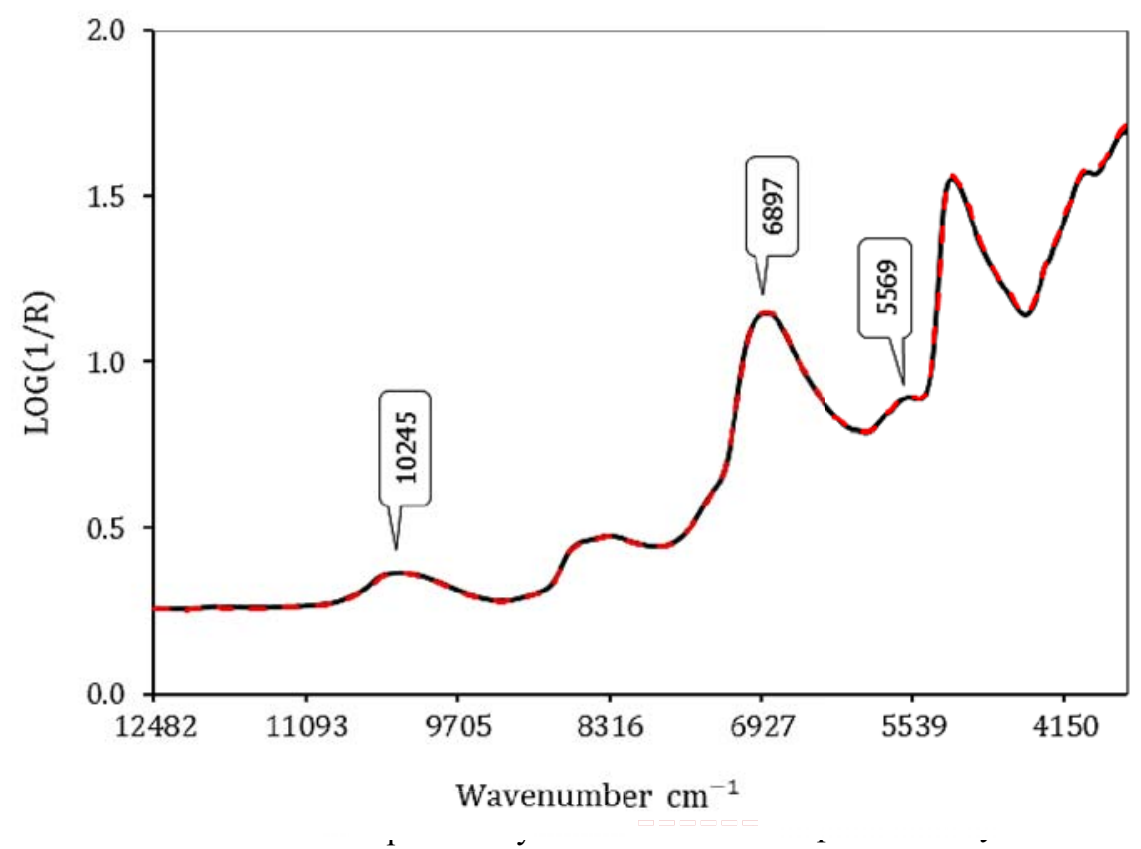

Fig. 1. The average spectra of mango samples scanned by FT-NIR spectrometer. 


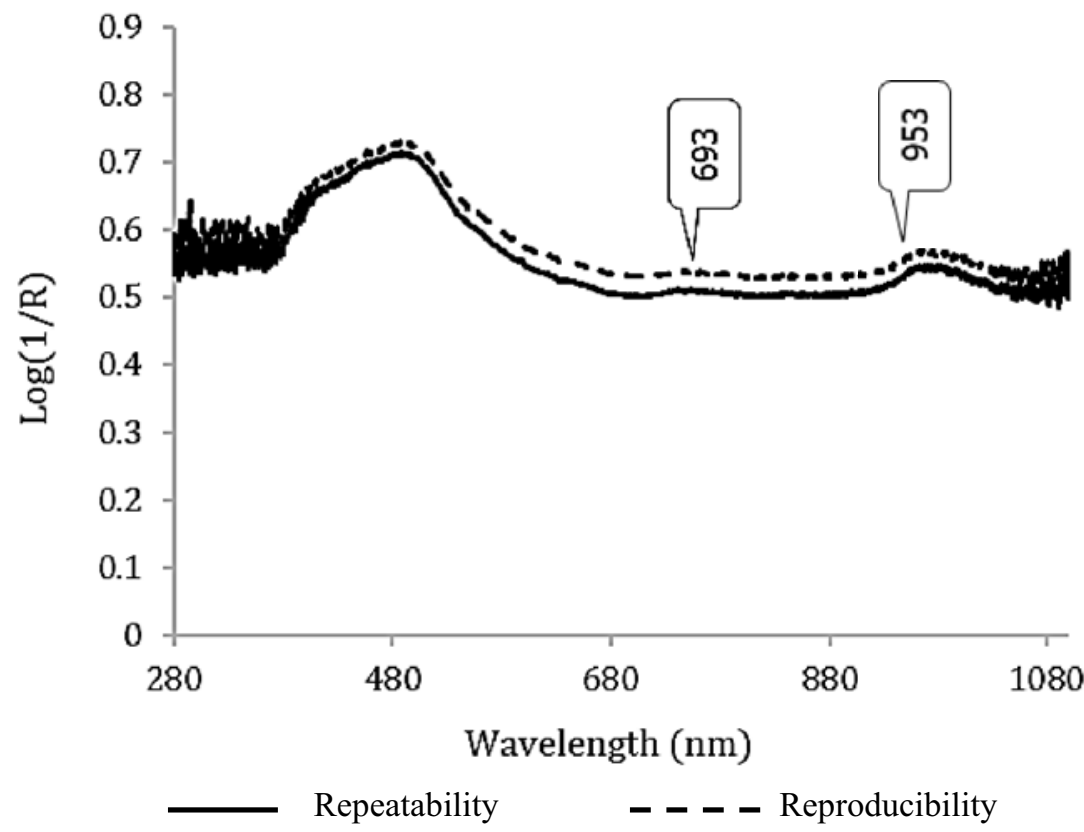

Fig. 2. The average spectra of mango samples scanned by UV-VIS-NIR spectrometer.

Table 1. Repeatability and reproducibility values of on-line and off-line scanning.

\begin{tabular}{|c|c|c|c|c|}
\hline \multirow[b]{2}{*}{ NIR } & \multicolumn{2}{|c|}{ Scanning method } & \multicolumn{2}{|c|}{ Reference method } \\
\hline & Repeatability & Reproducibility & Repeatability & $\mathbf{R}_{\text {max }}^{2}$ \\
\hline On-line & 0.00199 & 0.00279 & \multirow{2}{*}{0.2} & \multirow[t]{2}{*}{0.894} \\
\hline Off-line & 0.00993 & 0.00513 & & \\
\hline
\end{tabular}

\section{Conclusions}

From preliminary experiments by finding the repeatability and reproducibility of the mango fruits (Mangifera Indica CV. 'Nam dok mai si thong') scanning, the off-line scanning had less repeatability and reproducibility than the on-line scanning. The result indicated that off-line scanning is more precise than on-line scanning. The maximum coefficient of determination $\mathrm{R}^{2}{ }_{\text {max }}$ of the measuring instrument at 0.894 .

Therefore, it could be concluded that the near infrared spectroscopy protocol developed with the proposed reference method could be used for creating a model to predict the amount of soluble solids of mangoes.

\section{References}

1. Agricultural extension group. Export information of nam dok mai mango export market.2019 [cited 2019 April 20]. Available at: http://www.chiangmai.doae.go.th.

2. Information and communication technology center.2020 [updated: 2020 Jan 15; cited 2019 Aug 12]. Available: http://www.doa.go.th.

3. S. Sirinnapa., J. Sornsrivichai, S. Kawano, Postharvest Biol. Technol. 31, 137 (2004) 
4. G.A. Hernández, Y. He, A.G. Pereira, J. Sci. Food Agric. 77, 313 (2006)

5. S. Kumpoun, S. Phatnibool, Comput Electron Agric 113, 44 (1992) 